\title{
Comparative Study of Structural Reliability Assessment Methods for Fixed Offshore Structures
}

\author{
E. Mat Soom ${ }^{1}$, M.K. Abu Husain ${ }^{2 *}$, N.I. Mohd Zaki ${ }^{2}$, N.A. Mukhlas ${ }^{2}$, S.Z.A. Syed Ahmad ${ }^{3}$, \\ N.U. Azman ${ }^{4}$ and Gholamhossein Najafian ${ }^{5}$ \\ 1 Repsol Oil and Gas Malaysia Limited, Jalan Ampang, 54450 Kuala Lumpur, Malaysia; \\ nizamsoom76@gmail.com \\ 2 Razak Faculty of Technology and Informatics, Universiti Teknologi Malaysia, Jalan Sultan Yahya Petra \\ 54100 Kuala Lumpur, Malaysia; noorirza.kl@utm.my, nazizah37@graduate.utm.my \\ 3 Faculty of Ocean Engineering Technology and Informatics, Universiti Malaysia Terengganu, 21030 Kuala \\ Nerus, Malaysia; s.zainal@umt.edu.my \\ 4 Brunei Shell Petroleum Company Sendirian Berhad, Jalan Utara, Penaga Seria KB2933. Negara Brunei \\ Darussalam; nuruluyuna@gmail.com \\ 5 School of Engineering, University of Liverpool, Brownlow Hill, Liverpool L69 3GH, United Kingdom; \\ najafian@liverpool.ac.uk \\ * Correspondence: mohdkhairi.kl@utm.my
}

\begin{abstract}
The oil and gas sector has recognised structural integrity assessment of ageing platform for prospective life extension as a rising concern, particularly in encountering the randomness of the harsh ocean environments. This condition leads to uncertainty in wave-in-deck load estimates and a high load level being imposed on offshore structures. This emphasises the necessity of enhanced reliability, as failure might result in inaccessibility because of the uncertainties related to long-distance services, such as accuracy of predictions of loads and responses. Even though the established guidelines present a fundamental assessment, additionally, comprehensive rules are required. This paper performed a reliability analysis incorporating practical approaches that can more accurately represent time-dependent structural deterioration. The following two procedures have been adopted by a majority of significant oil and gas operators to monitor the safety and integrity of these structures: a) Ultimate Strength Assessment (USA) method and b) Reliability Design Assessment $(\operatorname{ReDA})$ method. A comparison of these two reliability approaches was performed on selected ageing jacket structures in the region of the Malaysian sea. The comparative findings, namely, reserve strength ratio (RSR) at various years of the return period (RP) and ratio value for risk of failure regarding the probability of failure (POF), provided a check and balance in strengthening confidence in the results. The findings showed that the structural components might safely survive either using the USA and $R e D A$ method in such conditions, as the reliability indexes were determined to be satisfactory compared to allowable values from ISO 19902 design specifications. Therefore, these evaluations were determined to control the risk level of the structure during the remaining of its lifetime and undertake cost-effective inspections or mitigation strategies when necessary.
\end{abstract}

Keywords: offshore structures, reliability-based design assessment; global ultimate strength assessment; reserve strength ratio; probability of failure

\section{Abbreviations}

\begin{tabular}{|ll|}
\hline ALARP & As Low As Reasonably Practical \\
API & American Petroleum Institute \\
BS & Base Shear \\
DNV & Det Norske Veritas \\
\hline
\end{tabular}




\begin{tabular}{|ll|}
\hline HSSE & Health, Safety, Security, And Environment \\
ISO & International Standard Organisation \\
LRFD & Load And Resistance Factor Design \\
MSL & Mean Sea Level \\
NORSOK & Norsk Sokkels Konkuranseposisjon \\
POF & Probability of Failure \\
QRA & Quantitative Risk Analysis \\
RBA & Risk-Based Assessment \\
RBI & Risk-Based Inspection \\
ReDA & Reliability Design Assessment \\
RP & Return Period \\
RSR & Reserve Strength Ratio \\
SRA & Structural Reliability Assessment \\
TR & Target Reliability \\
USA & Ultimate Strength Assessment \\
USFOS & Ultimate Strength for Offshore Structures \\
WSD & Working Stress Design \\
\hline
\end{tabular}

\section{Introduction}

Over the past decades, Malaysia's upstream oil and gas industry has evolved in exploration and production technology by advancements to increase field productivity. As the oil price has declined, the field of development and operational expenditures have grown in line with enhanced oil recovery [1]. This enhanced oil recovery (reservoir) led to the demand in utilising ageing structures rising significantly beyond their intended design life in order to discover solutions to manage different financial risks [2]. In fact, 65 percent of offshore installations in Malaysian waters were discovered to have outlived their initial design life, ranging from 20 to 30 years [3]. Nowadays, this figure is over 85 percent operating beyond their initial lifespan. The necessity for comprehensive asset management has been increasing in regards to reliability, and integrity should not be negotiated [4]. Thus, the safety of these structures is essential due to the possibility of high risks associated with severe ocean storms [5].

Concerning this situation, there is indeed attention on a structure's ability to sustain environmental loadings in which it was not initially designed [6]. As an example, the strength performance of jacket legs platforms, which employs a steel framework to present additional stability at water depths less than 200 metres, continuously declines over time in relation to environmental factors and unexpected accidents [7]. Thus, a fixed offshore platform gradually deteriorates due to degradation issues like an extreme wave, current, fatigue, seismic effects, etc. [8]. Hostile and destructive oceanic conditions play a vital role in reducing strength capacity [9]. In agreement with Keprate and Ratnayake [10], degradation has become a primary issue in the oil and gas industry, causing substantial damage and collapse, as well as potentially dangerous working conditions. To assure a longer proper functioning state, oil and gas operators perform regular reassessments at ageing platforms due to the nature of degradation problems [2].

Besides that, further development of another platform is challenging to continue in the oil and gas business as resources become more limited reservoir [11]. As a result of the rising development costs, operators have been forced to raise oil and gas recovery efforts from current fields and expand further resources from surviving platforms [12]. This strategy has effectively produced substantial development costs, resulting in favourable project economics and making it practical to extract additional oil and gas resources in some circumstances. Concerning engineering of structures and economics perspectives, the structural reliability assessment (SRA) of fixed offshore platforms has been introduced [13]. The reliability analysis of technological systems and components in 
determining the probability of failure (POF) over a certain reference period is important to ensure precision in estimating its structural integrity and remaining service life [14].

Some studies have been undertaken on the reliability of Malaysian jacket platforms $[15,16]$ and other types of platforms from around the world in order to demonstrate the structure's capability and decide the valid mitigation measures [17]. Since the late 1990s, the Malaysian oil and gas industry has adopted a reliability strategy. Structure failure is foreseen when the strength capacity cannot withstand the maximum force (imposed loads) [18], which would need the evaluation of the possibility of extending the life of ageing platforms. Therefore, the implications of a failure might include interrupting production after the platform's prior life span has expired, substantial undersea modifications, and decommissioning $[19,20]$. In view of the continual production necessary after the first design life of these installations, the extension of life is unavoidable.

This article aimed to review the methods for the derivation of the POF on the structural reliability of an aged jacket platform in Malaysian waters. The two common methods used on an ageing platform were evaluated utilising Ultimate Strength Assessment (USA) and Reliability Design Assessment $(R e \mathrm{DA})$ procedures to assess life extension possibilities. As studied by Mat Soom, et al. [21], both procedures determine an appropriate offshore platform as the primary basis of analysis. These methods were then applied to a case study of an ageing jacket structure regarding the selected region of existing platforms. The USA and $R e \mathrm{DA}$ analysis results are necessary to provide a high level of confidence in structural strength for a longer design life alongside additional years of production. Overall, Section 2 represents the risk analysis implementation and the fundamental review of SRA, Section 3 delivers a valuable comparison of USA and ReDA techniques, Section 4 provides a comprehensive explanation of the test structure criteria, Section 5 compares the findings of the USA and $\operatorname{ReDA}$, and Section 6 describes the study's findings.

\section{Overview on the Offshore Structural Assessment}

A range of methods is utilised in the risk, reliability and safety disciplines. These disciplines are defined separately in another division; for example, Quantitative Risk Analysis, Probabilistic Risk Analysis, Probabilistic Safety Assessment, and Formal Safety Assessment are all fundamentally similar approaches [22]. The essential regulations in the offshore sector are commonly referred to as Quantitative Risk Analysis (QRA) and Structural Reliability Analysis (SRA).

\subsection{Implementation of Risk Analysis}

Risk analysis is a method of stimulating the inventive implementation of diverse approaches to perform systematic analysis methods and manage the uncertainty concerns associated with risk data [23]. The risk identification, assessment, monitoring, recommendation, and proper implementation are all part of this process. The different risk assessment procedures based on existing experiences have yielded more substantial advances and will provide more significant long-term advantages to the sector [24,25]. As a result, risk management must be perceived as essential to the effective completion of projects, even though it is frequently restricted by a lack of managerial practices and software tools [26]. A holistic comprehension of the many possible causes (risk) requires a clear definition of project performance objectives as significant considerations for successful project management and decision-making [27-29].

In comparison to other engineering fields, risk analysis is a relatively recent phenomenon. New disciplines require a considerable time for terminology to be accepted amongst professionals and even longer for widespread applicability [30]. QRA is determined via the entire risk to civilised health and safety [31], the ecosystem, and the property denoted by the installations. The followings are the significant elements in the analysis:

- Identification of hazards

- Assessment of probabilities /frequencies of initiation events

- Development of accident (how a starting event might become several unintentional occurrences)

- Consequence assessment (estimate of impacts of multiple accidents) 
- Calculation of risks

As shown in Figure 1, there are two forms of risk assessment (QRA): qualitative risk assessment and quantitative risk assessment. In accordance with Bai [32],Bai and Jin [33], qualitative is a subjective concept based on a set of fundamental situation rankings. The qualitative risk assessment is based on risk-based inspection (RBI), and a risk assessment matrix is employed to rate the hazards [34]. On the other hand, the quantitative evaluation stresses the point confidence interval and the probability of distribution based on the risk-based assessment (RBA) [35]. RBA also relies on design, analysis, and the most recently subsea and topsides risk assessments.

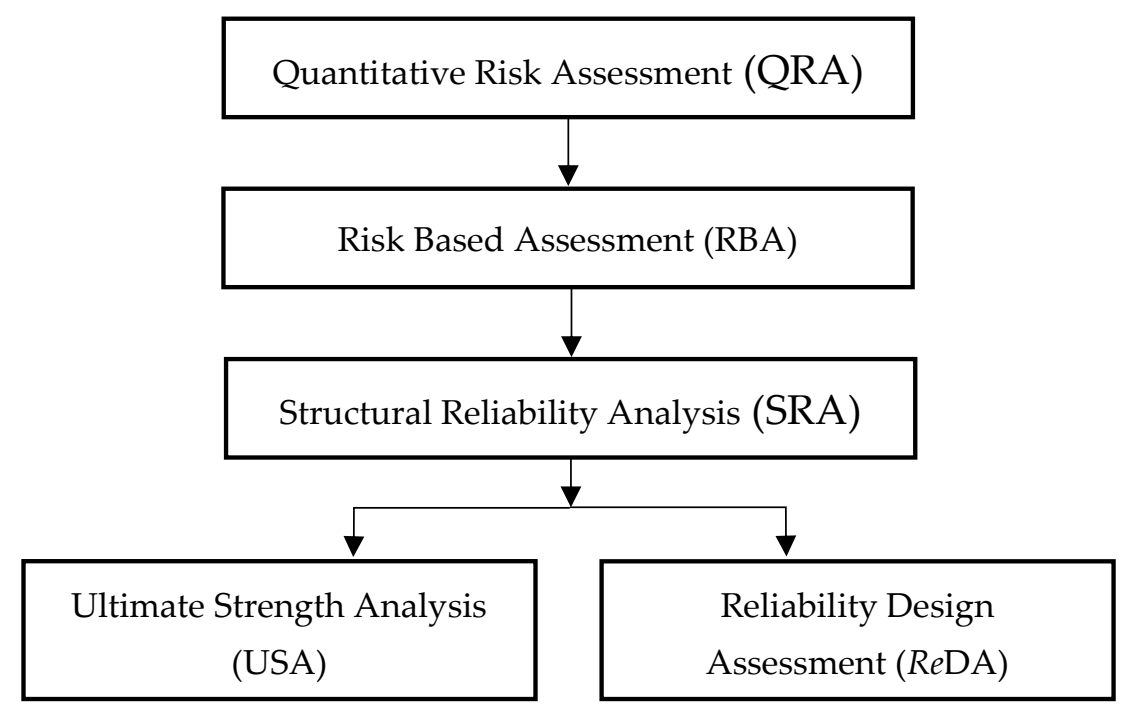

Figure 1. Quantitative risk assessment (QRA) with structural reliability assessment SRA

Regarding the RBA discipline, the risk assessment-based sequence of events can be accomplished in the Bow-Tie process [36]. It is part of the Health, Safety, Security, and Environment (HSSE) tools for As Low As Reasonably Practical (ALARP), usually utilised by oil and gas industries to assess and manage the risk. Bow-Tie is also a valuable tool for communicating about hazards and how to manage them properly [37]. Therefore, RBA is one of the main aspects of controlling barriers for avoiding the platform's collapse (Top event). The steps of Bow-Tie process are shown in Figure 2. In this study, four ageing platforms were considered: one with field subsidence and one platform without subsidence.

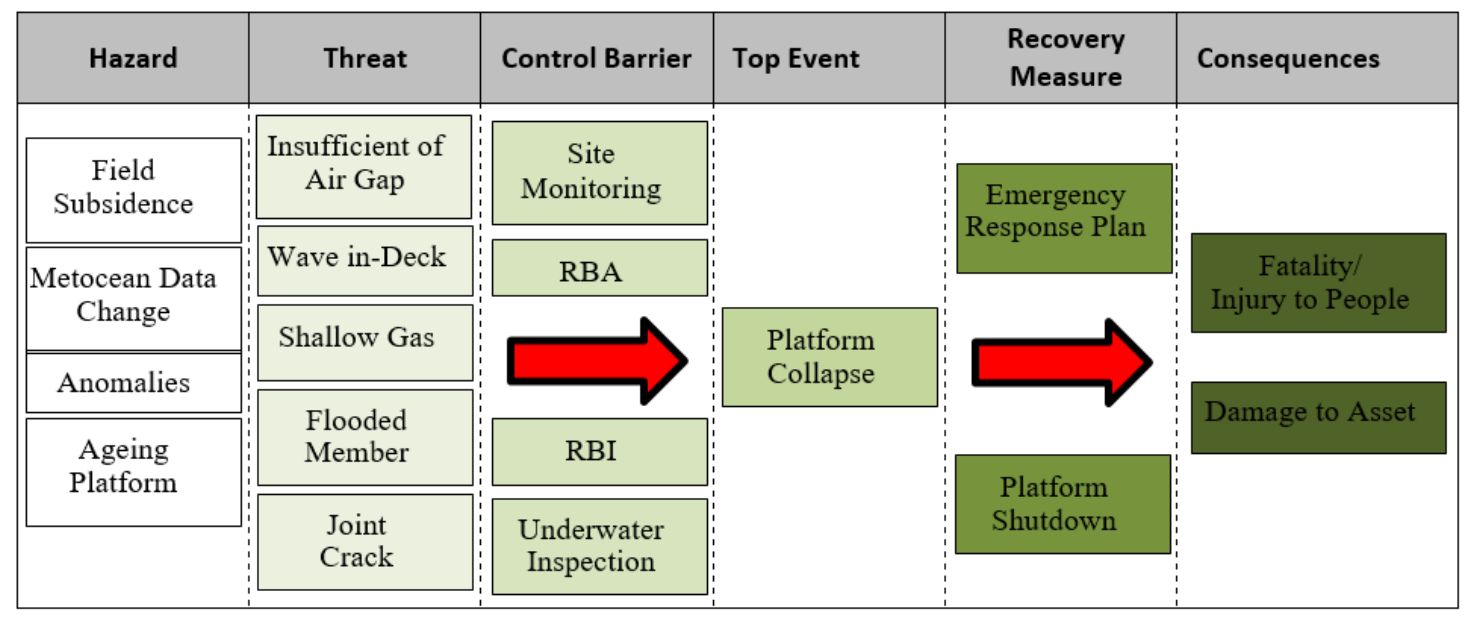

Figure 2. General bow-tie process 
According to Cameron and Raman [38],Khan, et al. [39], risk assessment has been deployed in various contexts to suggest that key elements of uncertainties, probabilities, or frequencies and implications have been addressed in some way. The assessment system in conventional scenarios is frequently imprecise due to various scenarios requiring history and historical data [40]. For that reason, the existing historical data is frequently precisely relevant to the subject analysed by SRA, which delivers a quantitative decision-making technique for evaluating the integrity of existing offshore platforms under Risk-Based Study (RBA) [41]. Moreover, evaluating the influence of more data, risk-reducing solutions, and modifications to the evaluated scenario is a significant aspect of a risk assessment [42].

SRA is regarded with assessing a structure's reliability or probability of failure $[43,44]$. Probabilistic models are used in the analysis [45]. SRA is also the planning and controlling behind relevant design calibration. It can be used in conjunction with legislature probabilistic-based mathematical models to recalculate design codes [46]. Thus, other legislature models were utilised to obtain the desired reliability level in conjunction with the proper code formulation.

\subsection{Structural Reliability Assessment (SRA)}

The load on offshore infrastructure arises primarily from two dimensions. According to Kharade and Kapadiya [47], the first is the self-weight of the jacket and deck structures, which is caused by gravity from semi-permanent and permanent equipment, storage commodities, human settlements, and operating loads. The majority of such loads do not change significantly over time and can be reliably predicted [48]. The second dimension of loading is environmental. It consists primarily of wind forces on the machinery, deck structures, opened members of the jacket, the impact of ocean waves and currents on the jacket structures, and, in rare situations, earthquake loading. These pressures change significantly over time, making it impossible to estimate the range of extreme climatic circumstances to which the structure will be subjected over its lifetime [49].

Predicting the mean wind velocity, wave height, wave period, and current velocity corresponding to the most severe storm is the initial stage in the in-place analysis and design of the intact structure $[50,51]$. However, a full description of the variance in sea state conditions over the structure's whole life is essential for fatigue damage evaluation [52]. This data was gathered through comprehensive oceanographic observations across several years prior to structural design and the application of statistical forecasting tools [53]. As mentioned in Section 2, this paper focused on fixed offshore structures located in Sarawak and Sabah regions. The five platforms were chosen based on the platform's global impact relating to substantial environmental loadings. The test substructure was defined as those employing a tripod, either a four-legged or an eight-legged structure with varying water depths reaching from $25 \mathrm{~m}$ to $130 \mathrm{~m}$ below mean sea level (MSL). Platforms range in age from 15 to 37 years old.

An offshore platform's primary design specification must fulfil the functionality demand for structural support of offshore oil and gas services, particularly both operational and extreme loadings [54]. At the design stage, a variety of loads must be considered, including permanent and operating loads, vibration, ship collisions, wind, wave, tide, current, fatigue, foundation responses, and seismic effects, amongst others [55]. Thus, substantial uncertainties of the environmental and material loads must be identified in order to appraise an existing offshore platform [56]. After a set period, material uncertainty may vary due to deterioration, particularly from a natural environment and corresponding fatigue [57]. The existing platforms are particular challenges, including damaged components, extra load from additional deck amenities, and extended design life from the initial design life $[58,59]$. Therefore, the strength of the structural system must be re-examined to observe whether operability and extensive safety regulations were complied with.

In the current rules of structural design, the code specifies a set of "nominal" loads, and material properties are based on the working stress for each form of component failure connected with a "factor safety" on the member strength [60]. As a result, load and resistance are considered singlevalued (and deterministic) numbers with no concern for variability. The defined safety factors are often obtained from experience and judgment rather than from any quantitative appraisal of the 
uncertainties associated with failure. Because numerous loads and material attributes are unpredictable (random) in nature, probabilistic approaches must be used in structural design [56]. It is now commonly accepted that sufficient safety is impossible to achieve in the context of uncertainty and that some hazard of inadequate structural performance must be permitted [61]. The primary goal of structural design is to assure, with a reasonable level of confidence, that a structure will not match improperly for its intended use at any time through its designated design life. Modern approaches of reliability-based design assist in achieving this goal.

Most measuring instruments are based on the nonlinear structural failure and structural reliability [62]. SRA is utilised to evaluate implications of uncertainties in load actions, resistances, and modelling of particular components of a structure. It can be carried out on individual structural components (local), as well as the entire structural system (global) [63]. Therefore, it might also benefit (re)calibrating partial action and resistance variables in uncommon or exceptional situations. Furthermore, SRA may be valuable for generating comparison data through the earliest design phase $[64,65]$. As a result, SRA provides a depth of confidence in the ability of a combination of components to perform as assigned, taking into account various uncertainties that arise with loads and resistances [66]. The 'probability of failure' or 'reliability', which is still widely acknowledged as a more realistic assessment of structural integrity, was used in these procedures to quantify the structure's safety [67].

The American Petroleum Institute API [68] has dedicated substantial work in recent years establishing a new "LRFD" design code in acknowledgement of the requirement for satisfactory estimation of uncertainties associated with the offshore structural design. This standard was recently made available for industry review. The load and resistance related to partial safety factors for system designs were generated from a reliability analysis assessing the numerous sources of uncertainties, and this code employs a "limit state design" principle [69]. In order to achieve reliability-based structural design, there are two types of suggested design techniques that may be used $[13,70]$. Both API-WSD working stress design practice and the API-LRFD load resistance factor design practice are granted by the API standard. A 'reliability-based format' is practised in the API-LRFD design approach [71,72]. Therefore, the new LRFD codes simplify regular design and convey a higher consistency in reliability between many members and under various load conditions [73].

Over a couple of decades, many studies have been conducted to understand ageing and its related mechanism better. Several initiatives have been exerted towards developing evaluation standards and a framework for extending the life of ageing structures [74]. The integration of evaluation techniques and frameworks for aged structures began in the mid-1990s with a section added to API RP 2A [75]. However, the input and approval criteria provided are related to US waters, the North Sea region, the Norwegian continental shelf, etc. Although several released standards were added to ISO 2394, ISO 13822, ISO 19902, NORSOK standard N-006 and DNV guideline [76-80], previous researches have minimum quantitative information associated with local regions [81]. Because various models, tools and equipment (software), and designer analysts are practised, there are typically differences in practises and hypotheses, which leads to the various mathematical models and statistical uncertainties being incorporated in the evaluation [82]. There is a legitimate requirement to better measure modelling uncertainty and acknowledge alternate approaches to integrate modelling uncertainty into reliability analysis.

Regarding the inconsistent assessments, there is a well-defined need to progress towards a set of principles, specifically in conjunction with structural integrity [83], in order to adopt a more reasonable approach. To address the issues mentioned above, this research reviewed two different methods for structural integrity evaluation to extend the life of aged offshore structures. The proposed framework included the theories and principles to anticipate remaining fatigue performance and assess structural capability in the Ultimate limit state (ULS), Serviceability limit state (SLS) and Accidental Limit State (ALS) during the whole prolonged service life (Nizamani, 2015). In this study, the recent analysis performed the quantitative risk-based assessment (RBA), which was used to calculate the structural reliability analysis (SRA) using the Ultimate Strength Assessment (USA) and Reliability Design Assessment (ReDA). The subsequent section explained the approaches' framework in further detail. 


\section{Ultimate Strength Assessment (USA) and Reliability Design \& Assessment (ReDA) Procedures}

The USA is an integrated approach designed to facilitate the re-evaluation of operations. The results of these analyses can support the interpretation of the failures of the structure and adequately identify the suitable preventive approach. In this article, two elements, Nonlinear Plastic Collapse (NPC) and Structural Reliability Evaluation (SRA) for global analysis, would be computed for global assessment. Since $\operatorname{ReDA}$ is an evaluation method for analysing structural reliability, guidelines for development and reassessment were generated from the necessary platform strength for the incident and associated with the probability of failure. Standards were established by decreasing risk to the lowest level (the ALARP system). Table 1 compared the structural reliability evaluation between USA and $\operatorname{ReDA}$ methods in terms of these two approaches.

Table 1. Comparison between USA and $R e D A$ procedures

\begin{tabular}{|c|c|c|c|c|c|c|c|}
\hline Method & $\begin{array}{c}\text { Remote } \\
\text { Area }\end{array}$ & $\begin{array}{c}\text { Uncertainty } \\
\text { Parameter } \\
\text { Development }\end{array}$ & $\begin{array}{l}\text { Number } \\
\text { of } \\
\text { Return } \\
\text { Period }\end{array}$ & $\begin{array}{l}\text { Methodology } \\
\text { Reassessment }\end{array}$ & $\begin{array}{c}\text { Type of } \\
\text { calculation }\end{array}$ & $\begin{array}{c}\text { Type of } \\
\text { Distribution }\end{array}$ & Final Output \\
\hline USA & $\begin{array}{c}\text { South } \\
\text { China } \\
\text { Sea }\end{array}$ & $\begin{array}{l}\text { Malaysian } \\
\text { water only }\end{array}$ & $\begin{array}{c}100 \\
\text { years }\end{array}$ & $\begin{array}{l}\text { Three (3) integrated } \\
\text { analyses, i.e. } \\
\text { nonlinear plastic } \\
\text { collapse (NPC), } \\
\text { member importance } \\
\text { analysis (MIA) and } \\
\text { structural reliability } \\
\text { assessment (SRA) }\end{array}$ & $\begin{array}{l}\text { Simplified } \\
\text { Structural } \\
\text { Reliability } \\
\text { Method } \\
\text { (Annual } \\
\text { Reliability } \\
\text { Index) }\end{array}$ & $\begin{array}{l}\text { Log-Normal } \\
\text { (Load Model } \\
\text { and Strength } \\
\text { Model) }\end{array}$ & $\begin{array}{c}\text { Reserve } \\
\text { Strength Ratio } \\
\text { (RSR), Base } \\
\text { Shear (BS) } \\
\text { and } \\
\text { Probability of } \\
\text { Failure (POF) } \\
\text { for } 100 \text { years } \\
\end{array}$ \\
\hline $\operatorname{ReDA}$ & $\begin{array}{c}\text { North } \\
\text { Sea }\end{array}$ & Worldwide & $\begin{array}{c}100 \\
\text { years, } \\
1000 \\
\text { years } \\
\text { and } \\
10,000 \\
\text { years }\end{array}$ & $\begin{array}{l}\text { This method consists } \\
\text { of Type I and II } \\
\text { uncertainties used to } \\
\text { determine the } \\
\text { probability of failure } \\
\text { (POF) for the } \\
\text { structure over its } \\
\text { remaining service life } \\
\text { by using a direct } \\
\text { combination, }\end{array}$ & $\begin{array}{c}\text { Convolution } \\
\text { Method } \\
\text { (Integrals } \\
\text { formulation) }\end{array}$ & $\begin{array}{c}\text { Exponential } \\
\text { (Load Model) } \\
\text { Normal } \\
\text { (Strength } \\
\text { Model) }\end{array}$ & $\begin{array}{c}\text { Reserve } \\
\text { Strength Ratio } \\
\text { (RSR), Base } \\
\text { Shear (BS) } \\
\text { and } \\
\text { Probability of } \\
\text { Failure (POF) } \\
\text { for Mean }\end{array}$ \\
\hline
\end{tabular}

The USA utilises a simplified technique based on the computations of Lognormal Distribution, whereas ReDA utilises the integral solution. Regarding USA practice, it is restricted to Malaysian waters because of the local parameter of bias and the local Coefficient of Variance (COV) used. Shell's running industry across the world has effectively adopted the $\operatorname{ReDA}$ practice. The $\operatorname{ReDA}$ utilises up to three RPs of 100, 1000, and 10000 years, whereas USA utilises only one RP of 100 years. In order to get a high level of confidence, it is advisable to compute with a long-term distribution that the platform has a minimum of two environmental loads for 100 years as compared with its earlier design of RP. ReDA was nonetheless computed for the average probability of failure (POF).

USA and ReDA methods were shown in the sequence diagram regarding the SRA development (refer to Figure 3). Both USA and ReDA procedures have a safety measure of standardised RSR and targeted reliability of POF. Then, nonlinear pushover analysis determined the RSR, base shear (BS), and ultimate loads. In conclusion, a computed POF associated with targeted reliability was compared with the USA (simplified approach), ReDA (convolution technique), and ISO 19902 regulation was achieved. 


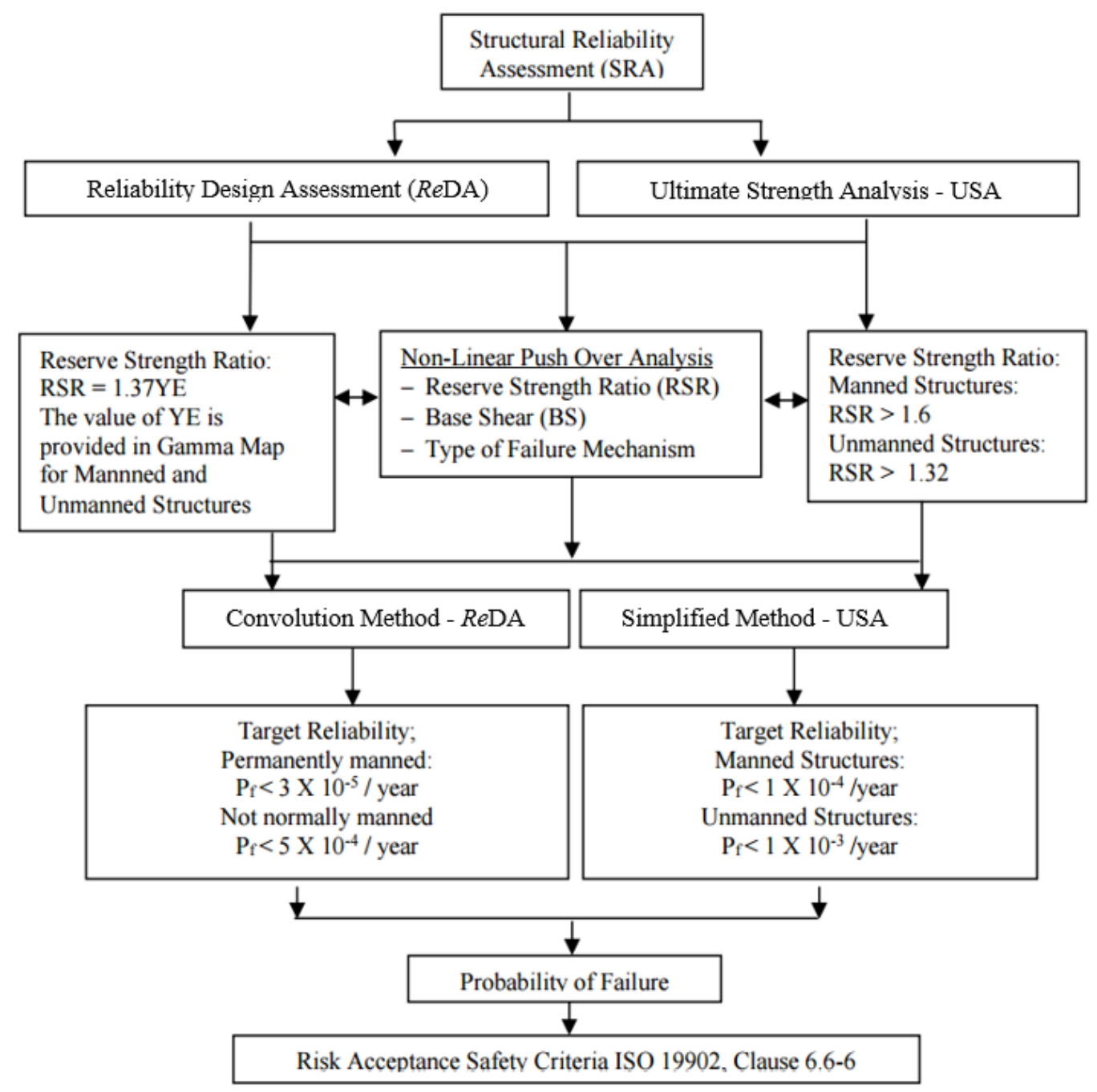

Figure 3. Details of USA and ReDA procedures

Based on the Hs (significant wave height) hindcast data from the 1940s to the 2000s, the patterned data of bias and COV was generated on different locations, whereby Sarawak Operation and Sabah Operation regions related to USA procedure. The provided bias and COV values were initially obtained using the Weibull Distribution Graph Analysis. The computed POF was based on a return period of 100 years. In contrast, ReDA analysis contained three different returns periods of 100, 1000 and 1000 years as a value of POF. This approach is based on Type I and Type II uncertainty used to calculate the structure's POF over the remaining life of the structure. However, the calculated POF was based on the average return period. More information on the methods for USA and $R e D A$ is available in Mat Soom, et al. [84].

\section{Test Structure Specification}

This analysis focused on the regions of Sarawak Operation (SKO) and Sabah Operation (SBO). For case studies, several sites and kinds of offshore platforms were considered. Deck level of test platforms were based on levelling survey installation(s) undertaken in previous years. These platforms consisted of subsidence platforms except P37D-4. Table 2 summarises the description of the platform specifications. 
Table 2. Platform specifications

\begin{tabular}{|c|c|c|c|c|c|}
\hline Platform & $\begin{array}{c}\text { Design Safety } \\
\text { Category }\end{array}$ & Bridge link & $\begin{array}{c}\text { Issue of } \\
\text { Subsidence } \\
\text { (Y/N - value) }\end{array}$ & $\begin{array}{c}\text { Number of } \\
\text { legs }\end{array}$ & $\begin{array}{c}\text { Average } \\
\text { Water Depth }\end{array}$ \\
\hline P88V-3 & Unmanned & Yes & $\mathrm{Y}-5.312 \mathrm{~m}$ & 3 legged & \multirow{3}{*}{$88 \mathrm{~m}$} \\
\hline P88Q-4 & Manned & Yes & $\mathrm{Y}-5.671 \mathrm{~m}$ & 4 legged & \\
\hline P88P-8 & Manned & Yes & $\mathrm{Y}-5.308 \mathrm{~m}$ & 8 legged & \\
\hline P37D-4 & Unmanned & No & $\mathrm{N}-0.103 \mathrm{~m}$ & 4 legged & $37 \mathrm{~m}$ \\
\hline P132D-4 & Unmanned & No & $Y-2.864 m$ & 4 legged & $132 \mathrm{~m}$ \\
\hline
\end{tabular}

In order to obtain a realistic result, the long-term analysis was analysed to predict the maximum load distribution in terms of RPs, i.e. 100, 1000 and 10000 years. According to PETRONAS Research and Scientific Services [85], the results were generated and given in this case study using Met-Ocean data provided by the Department of Petronas Carigali Sdn Bhd. The Met-ocean data have been produced from hindcast data and were based on the hydrodynamics of deep water. A minimum of eight directions of wave loadings were necessary for 4-legged and 8-legged platform types, however, for 3-legged platform types, a minimum of twelve directions, with an equal distance of $30^{\circ}$ between them.

\section{Comparison of the outputs from USA and $\operatorname{ReDA}$ procedures}

In order to achieve a high confidence level, five platforms were analysed for reserve strength ratio (RSR), and POF values with a comparison between both methods, which were USA and $R e D A$. The pushover analysis can be performed to determine whether the ultimate platform resistance exceeds the platform's capacity, RSR and base shear (BS) values. An approximate reliability measure of the platform in terms of POF can be established by determining the return period of the environmental load that the structure can withstand with the (lowest) calculated RSR. In this section, the results from the two methods have been tabulated in detail.

\subsection{Reserve Strength Ratio (RSR) and Base Shear (BS)}

Reserve strength ratio can be determined by the first 'significant' peak or the highest peak of the load-deformation curve as the 'collapse' RSR [63] from the result of software of Ultimate Strength for Offshore Structure (USFOS) [86,87]. For this study, for each selected platform, the worst direction (in degrees) of more considerable base shear based on the minimum or maximum water depth calculated was identified and selected before.

The results of RSR alongside base shear from USA and ReDA methods were recorded regarding various return periods in Table 3 with the worst direction for each platform. The RSR for every return period has been evaluated together with BS values. RSR is a load factor for a number of waves attacking the platform until collapse. The different result between these three return periods was where the lowest RSR at 10,000-years return period, base shear was the highest, and vice-versa when the RSR was highest. RSR and BS results were computed by software push over USFOS at selected return periods. 
Table 3. Reserve strength ratio, base shear and mode of failure from USFOS software

\begin{tabular}{|c|c|c|c|c|c|c|c|c|}
\hline \multirow{2}{*}{ Platform } & \multirow{2}{*}{$\begin{array}{l}\text { Mode of } \\
\text { Failure }\end{array}$} & \multirow{2}{*}{$\begin{array}{l}\text { Critical } \\
\text { Direction }\end{array}$} & \multicolumn{2}{|c|}{$\begin{array}{c}100 \text { years } \\
\text { Return Period }\end{array}$} & \multicolumn{2}{|c|}{$\begin{array}{c}1000 \text { years Return } \\
\text { Period }\end{array}$} & \multicolumn{2}{|c|}{$\begin{array}{c}10000 \text { years Return } \\
\text { Period }\end{array}$} \\
\hline & & & RSR & $\begin{array}{c}\text { BS } \\
(\mathbf{M N})\end{array}$ & RSR & $\begin{array}{c}\text { BS } \\
(\mathrm{MN})\end{array}$ & RSR & $\begin{array}{c}\text { BS } \\
(\mathrm{MN})\end{array}$ \\
\hline P88V-3 & $\begin{array}{l}\text { Punch } \\
\text { through }\end{array}$ & $90^{\circ}$ & 1.80 & 1.95 & 1.49 & 2.44 & 1.19 & 2.93 \\
\hline P88Q-4 & $\begin{array}{l}\text { Punch } \\
\text { through }\end{array}$ & $90^{\circ}$ & 2.89 & 2.98 & 2.03 & 5.14 & 1.18 & 7.32 \\
\hline P88P-8 & $\begin{array}{l}\text { Punch } \\
\text { through }\end{array}$ & $270^{\circ}$ & 4.13 & 7.69 & 3.03 & 11.74 & 1.93 & 15.78 \\
\hline P37D-4 & $\begin{array}{l}\text { Punch } \\
\text { through }\end{array}$ & $221.6^{\circ}$ & 2.70 & 2.17 & 2.19 & 2.79 & 1.68 & 3.40 \\
\hline P132D-4 & $\begin{array}{l}\text { Punch } \\
\text { through }\end{array}$ & $45^{\circ}$ & 1.73 & 20.44 & 1.50 & 26.55 & 1.28 & 32.65 \\
\hline
\end{tabular}

The RSR results for 100 years at minimum, 1000 years at medium, and 10000 years return period at abnormal/extreme conditions are presented in Figure 4. It shows that all RSR values (for all test platforms) associated 100 years were above or exceeded both acceptable safety criteria limit for USA and ReDA. In comparison, for 1000 years return period only two platforms were above and exceeded both acceptance safety criteria, which were P88P-8 and P37D-4 Platforms. Those for 10000 years return period showed only that the P37D-4 platform exceeded both acceptance safety criteria.

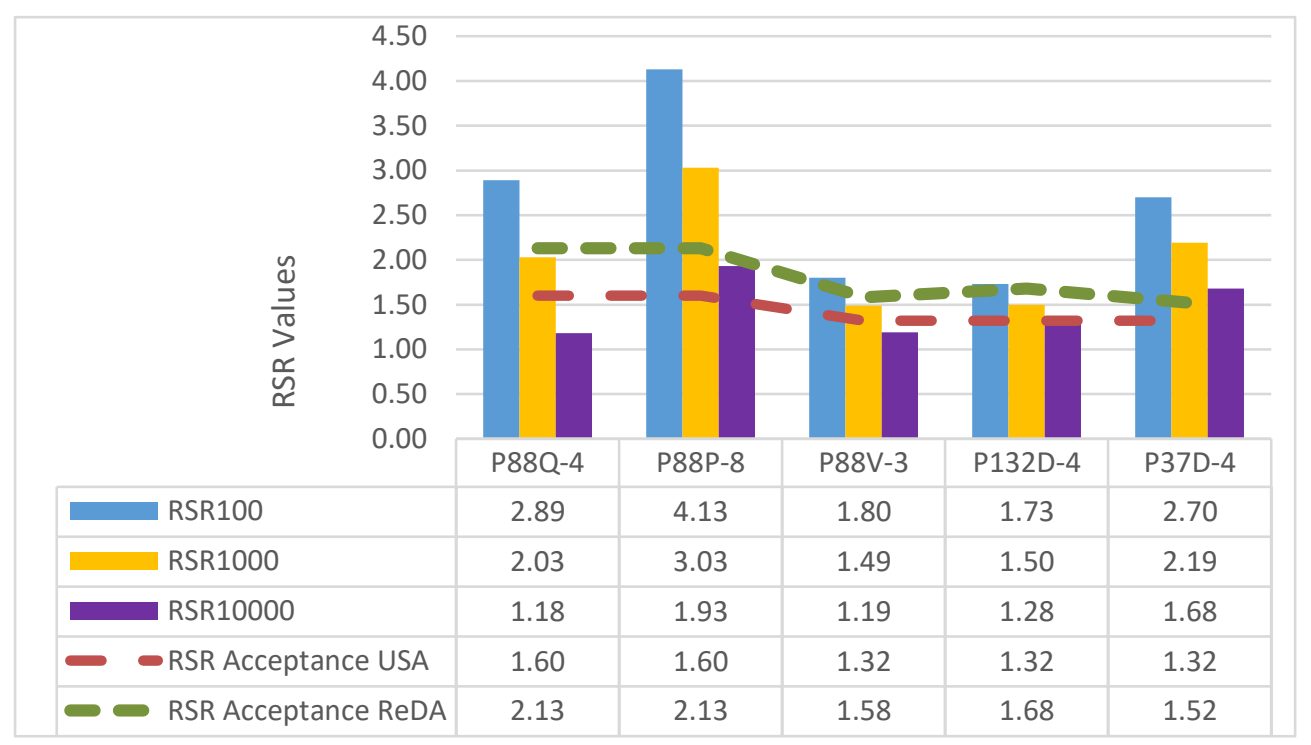

Figure 4. Comparison of reserve strength ratio and base shear at different return periods

\subsection{Probability of Failure (POF)}

In this section, the POF was discussed, where the probability of structural failure was then evaluated by examining a limited number of significant sequences of member failures that produce the collapse of the structures. The structure will eventually survive, given one or more of its members (Mat Soom et al., 2015). The evaluation concerning the probability of failure (POF) was only examined for beyond than 100 years return period (RP), where the potential for the platform to collapse exceeded at this return period $(\mathrm{RP})$. 
As shown in Figure 5, the probability of failure (POF) of target reliability (TR) limit for USA and $R e \mathrm{DA}$ was highlighted following the line in red and purple. In contrast, the calculated probability of failure (POF) for USA and the probability of failure (POF) for ReDA are highlighted as a bar chart. In the line of structural study, only one platform (P37D-4) had significantly less value of probability of failure (POF) using simplified method (USA) as well as convolution method (ReDA) in comparison with the probability of failure (POF) and its corresponding target reliability (TR). This platform had a ratio of 0.000233 (USA) and $0.000000(R e D A)$ times risk of failure compared to target reliability for USA and ReDA, as showed by the tabulated results in Table 4. Due to this reason, this platform was very unlikely to fail beyond 100 years return period (RP).

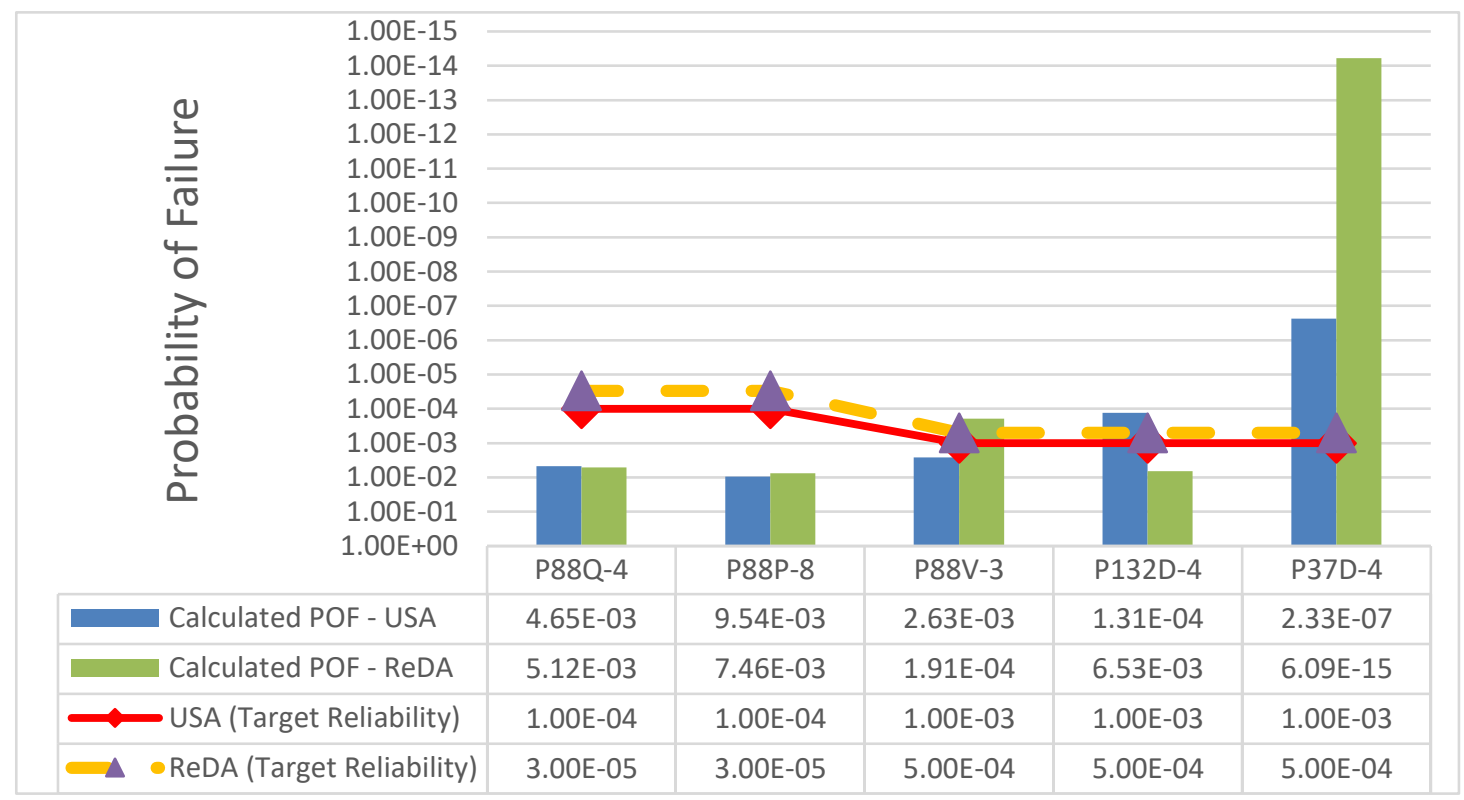

Figure 5. Comparison of the probability of failure from USA and ReDA procedures with their corresponding target reliability

Two platforms, P88V-3 and P132D-4, passed either probability of failure (POF) target reliability for USA and ReDA. P88V-3 had a lower ratio of 2.63 times risk of failure for both calculated USA and ReDA comparison against both target reliability. Similarly, for Platform P132D-4, it had less ratio of 13 times risk of failure for calculated USA and ReDA comparison against both target reliability. The ratio in conformity is shown in Table 4 . Thus, both were still considered unlikely to fail beyond 100 years above the return period (RP). While two platforms, P88Q-4 and P88P-8, had a very high significant ratio value for risk of failure either USA or ReDA target reliability and potentially very likely to fail platforms at beyond 100 years return period (RP).

Table 4. Ratios between the probability of failure (calculated from USA and ReDA procedures) with their corresponding target reliability

\begin{tabular}{|c|c|c|c|c|c|c|}
\hline Platform & $\begin{array}{c}\text { Calculated } \\
\text { probability } \\
\text { of failure } \\
\text { (USA) }\end{array}$ & $\begin{array}{c}\text { Target } \\
\text { Reliability } \\
\text { (USA) }\end{array}$ & $\begin{array}{c}\text { Ratio } \\
\text { Calc. POF /TR } \\
\text { (USA) }\end{array}$ & $\begin{array}{c}\text { Calculated } \\
\text { probability } \\
\text { of failure } \\
(\text { ReDA })\end{array}$ & $\begin{array}{c}\text { Target } \\
\text { Reliability } \\
(\boldsymbol{R e D A})\end{array}$ & $\begin{array}{c}\text { Ratio } \\
\text { Calc. POF } \\
\text { /TR (ReDA) }\end{array}$ \\
\hline P88Q-4 & $4.65 \mathrm{E}-03$ & $1.00 \mathrm{E}-04$ & 46.500000 & $5.12 \mathrm{E}-03$ & $3.00 \mathrm{E}-05$ & 170.600000 \\
\hline P88P-8 & $9.54 \mathrm{E}-03$ & $1.00 \mathrm{E}-04$ & 95.400000 & $7.46 \mathrm{E}-03$ & $3.00 \mathrm{E}-05$ & 248.600000 \\
\hline P88V-3 & $2.63 \mathrm{E}-03$ & $1.00 \mathrm{E}-03$ & 2.630000 & $1.91 \mathrm{E}-04$ & $5.00 \mathrm{E}-04$ & 0.300000 \\
\hline P132D-4 & $1.31 \mathrm{E}-04$ & $1.00 \mathrm{E}-03$ & 0.131000 & $6.53 \mathrm{E}-03$ & $5.00 \mathrm{E}-04$ & 13.000000 \\
\hline P37D-4 & $2.33 \mathrm{E}-07$ & $1.00 \mathrm{E}-03$ & 0.000233 & $6.09 \mathrm{E}-15$ & $5.00 \mathrm{E}-04$ & 0.000000 \\
\hline
\end{tabular}




\subsection{ISO 19902 (Exposure Level)}

POF exposure level can be determined by referring to ISO 19902 Clause 6.6 (ISO 2007). All test platforms (P88Q-4, P88V-3, P132D-4 and P37D-4) were under the L2 exposure level, which was S2 or S3 life safety category and C2 medium consequences. However, P88P-8 was under L1 exposure level, which was the S1 life safety category and C1 medium consequences. Figure 6 showed that the probability of failure (POF) was in line with the limit of ISO 19902 constant values at 5.00E-4 @ POF exposure level L2 for all platforms, respectively. The subsequent target reliability (TR) was shown in Table 5. Only one platform significantly reduced POF for both USA and ReDA than ISO 19902 target reliability limit. Thus, this platform P37D-4 had a ratio of 0.0 times risk of failure for both calculated probability of failure (POF). Thus, this platform was Extremely Reliable and Clearly Acceptable from Global Assessment and Analysis, referring to ISO 19902 beyond 100 years return period (RP).

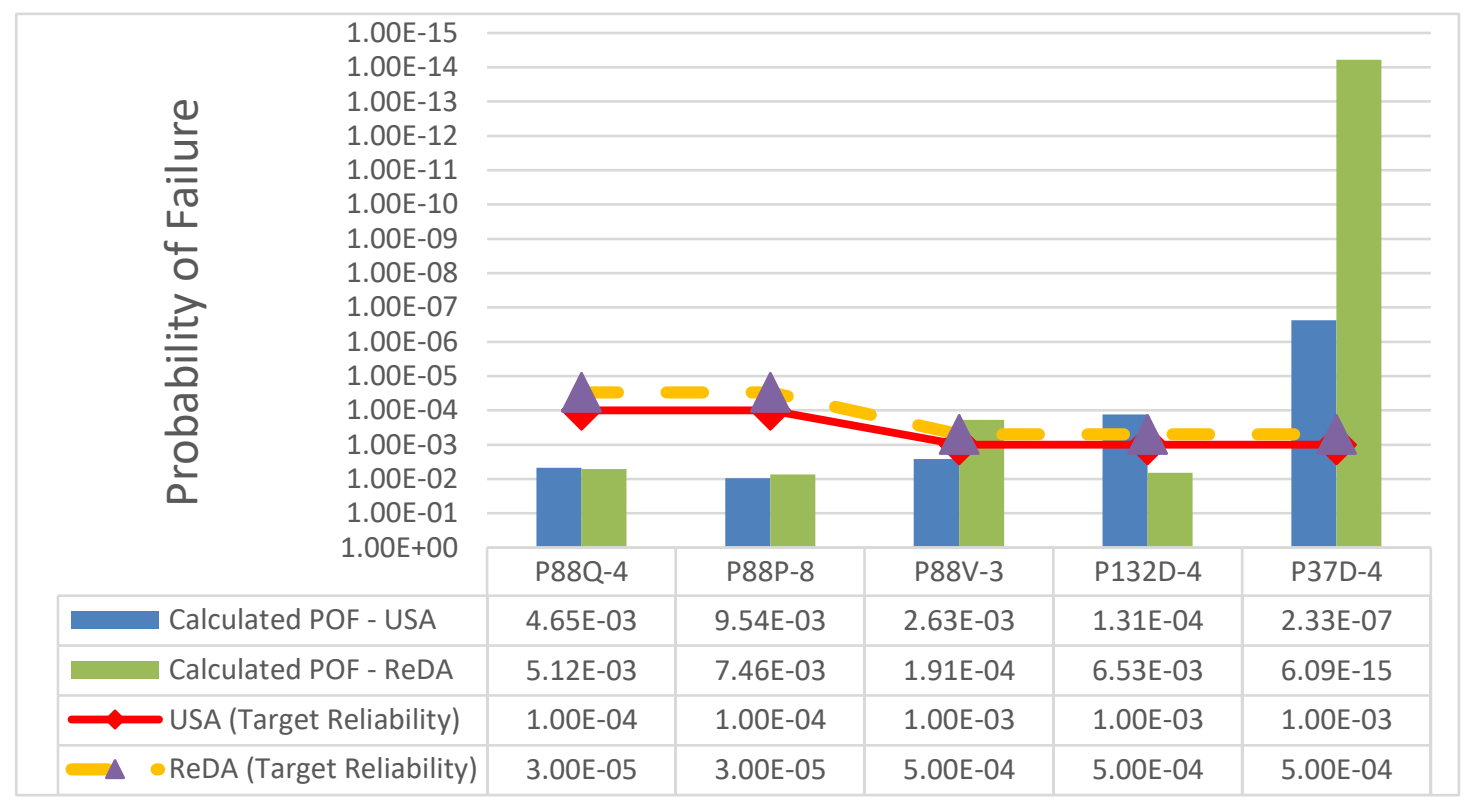

Figure 6. Comparison of the probability of failure from USA and ReDA procedures against iso 19902 (exposure level) target reliability

Two platforms, P88V-3 and P132D-4, passed either probability of failure (POF) target reliability for USA and ReDA. However, P88Q-4 did not meet the target reliability for ISO 19902. In terms of ratio analysis, three of them had marginal ratio value times risk of failure comparison against ISO 19902. Thus, three of them were still considered Reliable and Clearly Acceptable from Global Assessment and Analysis beyond 100 years return period (RP). Finally, P88P-8's USA and ReDA based calculations had very high significant ratio value for risk of failure, and it was Extremely Not Reliable and Not Clearly Acceptable from Global Assessment and Analysis at beyond 100 years return period (RP).

The smaller number of jacket's legs contributed to less base shear and gave minor impact to the ratio between USA and ReDA in comparison against ISO 19902. Only one platform (P37D-4) without subsidence issue significantly impacted the result where no ratio value for risk of failure. However, water depth did not influence the probability of failure (POF and return period (RP). 
Table 5. Ratios between the probability of failure (calculated from USA and ReDA procedures) and the probability of failure from ISO 19902

\begin{tabular}{|c|c|c|c|c|c|}
\hline Platform & $\begin{array}{c}\text { Calculated } \\
\text { probability of } \\
\text { failure (USA) }\end{array}$ & $\begin{array}{c}\text { Calculated } \\
\text { probability of } \\
\text { failure (ReDA) }\end{array}$ & $\begin{array}{c}\text { Target } \\
\text { Reliability } \\
\text { (ISO } \\
\mathbf{1 9 9 0 2} \text { ) }\end{array}$ & $\begin{array}{c}\text { Ratio } \\
\text { (Calc. POF } \\
\text { USA / ISO } \\
\mathbf{1 9 9 0 2})\end{array}$ & $\begin{array}{c}\text { Ratio } \\
\text { (Calc. POF } \\
\text { ReDA / ISO } \\
\mathbf{1 9 9 0 2})\end{array}$ \\
\hline P88Q-4 & $4.65 \mathrm{E}-03$ & $5.12 \mathrm{E}-03$ & $5.00 \mathrm{E}-04$ & 9.300000 & 10.230000 \\
\hline P88P-8 & $9.54 \mathrm{E}-03$ & $7.46 \mathrm{E}-03$ & $3.00 \mathrm{E}-05$ & 318.000000 & 248.670000 \\
\hline P88V-3 & $2.63 \mathrm{E}-03$ & $1.91 \mathrm{E}-04$ & $5.00 \mathrm{E}-04$ & 5.260000 & 0.380000 \\
\hline P132D-4 & $1.31 \mathrm{E}-04$ & $6.53 \mathrm{E}-03$ & $5.00 \mathrm{E}-04$ & 0.260000 & 13.070000 \\
\hline P37D-4 & $2.33 \mathrm{E}-07$ & $6.09 \mathrm{E}-15$ & $5.00 \mathrm{E}-04$ & 0.000000 & 0.000000 \\
\hline
\end{tabular}

\section{Conclusion}

The conclusions of the conducted research are as follows:

- USA and ReDA methods have been accepted by most of the marine operators in the offshore industry to manage their structures' safety, integrity, and reliability.

- It was noted that both methods were based on the design code for fixed offshore structures by utilising the limit state equation of probabilistic models.

- The USA method was limited to Malaysian waters due to its use of the local parameters of bias and coefficient of variance (COV). The calculation was based on the simplified method as normal distribution and considers only a 100-year return period.

- The ReDA method has been successfully implemented in the North Sea and worldwide facilities using the integral equation method. $R e \mathrm{DA}$ was applied for three different return periods (100, 1000 and 10,000 years) as long-term distribution response.

- All tested platforms were designed based on 100 years return period during the initial design. Based on the probability of failure result above, comparison at sections 5.2 and 5.3, all the tested platforms were reliable and acceptable for 100 years return period and below only.

- Consequently, it was better to calculate with long-term distribution for the platform to experience at least two environmental loading at different return periods to get a high confidence level. However, the result of 100 years return period will be compared with the initial return period, which is of paramount importance.

- According to the result obtained based on different offshore structures themselves, both procedures were proven to increase reliability. Thus, the safety of these assets was sustained

- The precision and efficiency of these methods will benefit the industry, particularly operators, to make decisions and, more precisely, to describe action plans as part of managing their business risks. The findings of these analyses may assist comprehension of the structure failure mechanism accurately and effectively describe the main kind of mitigation.

Author Contributions: E. was as the leading author of the original draft preparation, undertook this research as an ex-staff of Petronas Carigali Sdn Bhd.; M.K. and N.I contributed to the review, methodology, discussion and funding acquisition; N.A. reviewed the literature based on reliability assessment; S.Z.A. wrote, revised and edited the original draft paper; N.U. discussed and shared knowledge about the results achieved; G. was supervision the study.

Funding: This study was financially supported by the Universiti Teknologi Malaysia (Malaysia) [grant number: Q.K130000.2456.09G41 and Q.K130000.2456.09G36] and the Ministry of Higher Education Malaysia [grant number: R.K130000.7856.5F248 and R.K130000.7856.5F021], which is gratefully acknowledged.

Acknowledgments: The authors would like to acknowledge the support of academic and industrial establishments they represent.

Conflicts of Interest: The authors declare no conflict of interest. 


\section{References}

1. Adu, E.; Zhang, Y.; Liu, D. Current situation of carbon dioxide capture, storage, and enhanced oil recovery in the oil and gas industry. The Canadian Journal of Chemical Engineering 2019, 97, 1048-1076.

2. Animah, I.; Shafiee, M.; Simms, N.; Erkoyuncu, J.A.; Maiti, J. Selection of the most suitable life extension strategy for ageing offshore assets using a life-cycle cost-benefit analysis approach. Journal of Quality in Maintenance Engineering 2018.

3. Ayob, M.S.; Kajuputra, A.E.; Mukherjee, K.; Wong, B.S. Global ultimate strength assessment of existing offshore jacket structures. In Proceedings of Offshore Technology ConferenceAsia.

4. Aeran, A.; Siriwardane, S.C.; Mikkelsen, O.; Langen, I. A framework to assess structural integrity of ageing offshore jacket structures for life extension. Marine Structures 2017, 56, 237259.

5. Abaei, M.M.; Arzaghi, E.; Abbassi, R.; Garaniya, V.; Chai, S.; Khan, F. A robust risk assessment methodology for safety analysis of marine structures under storm conditions. Ocean Engineering 2018, 156, 167-178.

6. Asgarian, B.; Zarrin, M.; Sabzeghabaian, M. Effect of foundation behaviour on steel jacket offshore platform failure modes under wave loading. Ships and Offshore Structures 2019, 14, 570-581.

7. Ersdal, G.; Sharp, J.; Galbraith, D. Ageing accidents: suggestion for a definition and examples from damaged platforms. In Proceedings of International Conference on Offshore Mechanics and Arctic Engineering; p. V005T003A018.

8. Shabakhty, N.; Boonstra, H.; Van Gelder, P. System reliability of jack-up structures based on fatigue degradation. T Bedford \& van Gelder (Eds.), Safety and Reliability 2003, 1437-1445.

9. Wright, I. Ageing and life extension of offshore oil and gas installations. In Proceedings of SPE Offshore Europe Oil and Gas Conference and Exhibition.

10. Keprate, A.; Ratnayake, R.C. Fatigue and fracture degradation inspection of offshore structures and mechanical items: the state of the art. In Proceedings of International Conference on Offshore Mechanics and Arctic Engineering; p. V004T003A018.

11. Ersdal, G.; Sharp, J.V.; Stacey, A. Ageing and Life Extension of Offshore Structures: The Challenge of Managing Structural Integrity; John Wiley \& Sons: 2019.

12. Brandt, H.; Sarif, M. Life extension of offshore assets-balancing safety \& project economics. In Proceedings of SPE Asia Pacific Oil and Gas Conference and Exhibition.

13. Nezamian, A.; Nicolson, R.J.; Iosif, D. State of Art in Life Extension of Existing Offshore Structures. In Proceedings of International Conference on Offshore Mechanics and Arctic Engineering; pp. 165-174.

14. Zettlemoyer, N. Life extension of fixed platforms. Tubular Structures XIII November 2010.

15. Fadly, M. Sensitivity study of environmental load to reliability index for Malaysian region. MS. c. Dissertation, Universiti Teknologi PETRONAS, Malaysia, 2011.

16. Kurian, V.; Nizamani, Z.; Liew, M.; Wahab, M. Failure Probabilities for Jacket Platform Subjected to Wave and Current. In Proceedings of Proceedings of the International Conference on Civil, Offshore and Environmental Engineering. 
17. Shabakhty, N. Durable reliability of jack-up platforms: The impact of fatigue, fracture and effect of extreme environmental loads on the structural reliability. 2004.

18. Bea, R.; Xu, T.; Stear, J.; Ramos, R. Wave forces on decks of offshore platforms. Journal of Waterway, Port, Coastal, and Ocean Engineering 1999, 125, 136-144.

19. Day, M.; Gusmitta, A. Decommissioning of offshore oil and gas installations. In Environmental Technology in the Oil Industry, Springer: 2016; pp. 257-283.

20. Ekins, P.; Vanner, R.; Firebrace, J. Decommissioning of offshore oil and gas facilities: A comparative assessment of different scenarios. Journal of environmental management 2006, 79, 420-438.

21. Mat Soom, E.; Abu Husain, M.K.; Mohd Zaki, N.I.; Mohd Nor, K.; Ayob, M.S.; Najafian, G. Global Ultimate Strength Assessment (GUSA) for Lifetime Extension of Ageing Offshore Structures. 2015.

22. El-Reedy, M.A. Offshore Structures: Design, Construction and Maintenance; Gulf Professional Publishing: 2019.

23. Moan, T. Reliability-based management of inspection, maintenance and repair of offshore structures. Structure and Infrastructure Engineering 2005, 1, 33-62.

24. Stewart, G. Reassessment of Fixed Offshore Structures. Encyclopedia of maritime and offshore engineering 2017, 1-17.

25. Stewart, G.; Manzocchi, M. Recent Developments in Probabilistic Pushover Models for The Reliability Re-Assessment of Fixed Offshore Structures. Safety and Reliability 2018, 38, 3-31, doi:10.1080/09617353.2018.1545416.

26. Kjellén, U. Adapting the application of risk analysis in offshore platform design to new framework conditions. Reliability Engineering \& System Safety 1998, 60, 143-151.

27. Pritchard, C.L.; PMP, P.-R. Risk management: concepts and guidance; Auerbach Publications: 2014.

28. Dallas, M.; Director, A. Management of Risk: Guidance for Practitioners and the international standard on risk management, ISO 31000: 2009. White Paper, http://www. best-managementpractice. com/gempdf/management_of_risk_guidance_for_practitioners_and_the_international_ standard_on_risk_management_iso31000_2009.pdf, accesat la 2013, 5, 2015.

29. Stelzenmüller, V.; Coll, M.; Mazaris, A.D.; Giakoumi, S.; Katsanevakis, S.; Portman, M.E.; Degen, R.; Mackelworth, P.; Gimpel, A.; Albano, P.G. A risk-based approach to cumulative effect assessments for marine management. Sci Total Environ 2018, 612, 1132-1140.

30. Guédé, F. Risk-based structural integrity management for offshore jacket platforms. Marine Structures 2019, 63, 444-461.

31. Skogdalen, J.E.; Vinnem, J.E. Quantitative risk analysis offshore-human and organizational factors. Reliability Engineering \& System Safety 2011, 96, 468-479.

32. Bai, Y. Marine structural design; Elsevier: 2003.

33. Bai, Y.; Jin, W.-L. Marine Structural Design, 2nd ed.; Elsevier Science: 2016.

34. Thodi, P.; Khan, F.; Haddara, M. Risk based integrity modeling of offshore process components suffering stochastic degradation. Journal of Quality in Maintenance Engineering 2013.

35. Aven, T. A semi-quantitative approach to risk analysis, as an alternative to QRAs. Reliability Engineering \& System Safety 2008, 93, 790-797. 
36. Mokhtari, K.; Ren, J.; Roberts, C.; Wang, J. Application of a generic bow-tie based risk analysis framework on risk management of sea ports and offshore terminals. Journal of hazardous materials 2011, 192, 465-475.

37. Melchers, R.E. On the ALARP approach to risk management. Reliability Engineering \& System Safety 2001, 71, 201-208.

38. Cameron, I.T.; Raman, R. Process systems risk management; Elsevier: 2005

39. Khan, F.; Hashemi, S.J.; Paltrinieri, N.; Amyotte, P.; Cozzani, V.; Reniers, G. Dynamic risk management: a contemporary approach to process safety management. Current opinion in chemical engineering 2016, 14, 9-17.

40. Rowe, T.; Beard, S. Probabilities, methodologies and the evidence base in existential risk assessments. 2018.

41. Fayazi, A.; Aghakouchak, A. Reliability Based Assessment of Existing Fixed Offshore Platforms Located in the Persian Gulf. 2015.

42. Chandrasekaran, S. Offshore Structural Engineering: Reliability and Risk Assessment; CRC Press: 2017.

43. Mat Soom, E. Efficient Load Coefficient Method for Structural Reliability Assessment of Ageing Offshore Platforms. PhD Thesis, Universiti Teknologi Malaysia, 2018.

44. Mat Soom, E.; Abu Husain, M.K.; Mohd Zaki, N.I.; Mohd Nor, K.; Ayob, M.S.; Najafian, G. Lifetime Extension of Ageing Offshore Structures by Global Ultimate Strength Assessment (GUSA). Malaysian Journal of Civil Engineering 2018, 30.

45. Zio, E. Integrated deterministic and probabilistic safety assessment: concepts, challenges, research directions. Nuclear Engineering and Design 2014, 280, 413-419.

46. Aven, T. Risk assessment and risk management: Review of recent advances on their foundation. European Journal of Operational Research 2016, 253, 1-13.

47. Kharade, A.; Kapadiya, S. Offshore Engineering: An Overview of Types and Loadings On Structures. International Journal of Structural and Civil Engineering Research 2014, 1-13.

48. El-Reedy, M. Marine Structural Design Calculations; Butterworth-Heinemann: 2014.

49. Patel, M.H. Dynamics of Offshore Structures; Butterworth-Heinemann: 2013.

50. Hirdaris, S.; Bai, W.; Dessi, D.; Ergin, A.e.; Gu, X.; Hermundstad, O.; Huijsmans, R.; Iijima, K.; Nielsen, U.D.; Parunov, J. Loads for use in the design of ships and offshore structures. Ocean engineering 2014, 78, 131-174.

51. Huijsmans, R. Loads for use in the design of ships and offshore structures. Ocean Engineering; SE Hirdaris, W. Bai, D. Dessi, A. Ergin, X. Gu, OA Hermundstad, R. Huijsmans, K. lijima, UD Nielsen,]. Parunov, J, N. Fonseca, A. Papanikolaou, K. Argyriadis A. Incecik 2013.

52. Chandrasekaran, S. Dynamic Analysis and Design of Offshore Structures; Springer, New Delhi: 2015; Vol. 5.

53. Clauss, G.; Lehmann, E.; Östergaard, C. Offshore structures: volume I: conceptual design and hydromechanics; Springer: 2014.

54. Raheem, S.E.A. Nonlinear Response of Fixed Jacket Offshore Platform Under Structural and Wave Loads. Coupled Syst. Mech 2013, 2, 111-126.

55. Maria Bitner-Gregersen, E.; Ingolf Eide, L.; Hørte, T.; Skjong, R.; Bitner-Gregersen, E.M.; Eide, L.I. Ship and offshore structure design in climate change perspective; Springer Nature: 2013. 
56. Nizamani, Z. Environmental Load Factors and System Strength Evaluation of Offshore Jacket Platforms; Springer: 2015; Vol. 4.

57. Paik, J.K.; Melchers, R.E. Condition assessment of aged structures; Elsevier: 2014.

58. Aeran, A.; Siriwardane, S.C.; Mikkelsen, O.; Langen, I. Life Extension of Ageing Offshore Structures: A Framework for Remaining Life Estimation. In Proceedings of International Conference on Offshore Mechanics and Arctic Engineering; p. V03AT02A040.

59. Aeran, A.; Gudmestad, O.T. Guidelines for estimating remaining fatigue life of ageing offshore jacket structures. In Proceedings of International Conference on Offshore Mechanics and Arctic Engineering; p. V03AT02A039.

60. Idrus, A.B.; Potty, N.S.; Cossa, N.J.; Nizamani, Z.; Abdul Hamid, M.F. Resistance Parameters Statistics for Jacket Platforms in Offshore Malaysia. In Proceedings of The Twenty-first International Offshore and Polar Engineering Conference.

61. Negro, V.; López-Gutiérrez, J.-S.; Esteban, M.D.; Matutano, C. Uncertainties in the design of support structures and foundations for offshore wind turbines. Renewable energy 2014, 63, 125-132.

62. Ayob, M.; Mukherjee, K.; Kajuputra, A.; Wong, B.; Salleh, F. Requalification of offshore jacket structures in Malaysian waters. In Proceedings of Offshore Technology Conference-Asia.

63. Pueksap-anan, P. Sensitivity Study for RSR of Fixed Offshore Steel Type Platforms. Asian Institute of Technology, Thailand: Msc Thesis 2010.

64. Alessi, L.; Correia, J.A.; Fantuzzi, N. Initial Design Phase and Tender Designs of a Jacket Structure Converted into A Retrofitted Offshore Wind Turbine. Energies 2019, 12, 659.

65. Forbes, V.J. Structural System Reliability Framework for Fixed Offshore Platforms. PhD Thesis, University of Surrey, 2000.

66. Chakrabarti, S. Handbook of Offshore Engineering (2-volume set); Elsevier: 2005.

67. Haritos, N. Introduction to The Analysis and Design of Offshore Structures-An Overview. Electronic Journal of Structural Engineering 2007, 7, 55-65.

68. API. API Recommended Practice 2A-WSD Planning, Designing, and Constructing Fixed Offshore Platforms-Working Stress Design; American Petroleum Institute: Washington, USA, 2014.

69. Verma, A.K.; Ajit, S.; Karanki, D.R. Reliability and safety engineering; London : Springer-Verlag: 2016.

70. Nezamian, A.; Morgan, P.M. Performance-based Seismic Design of Fixed Offshore Platforms and Comparison with ISO and API Seismic Design Guidelines. In Proceedings of The Twenty-fourth International Ocean and Polar Engineering Conference.

71. San Tint, A. Reliability Analysis of the Final Design of a Fixed Offshore Jacket. Master Thesis, Asian Institute of Technology, 2015.

72. Fakhruddin, K.A. Reliability Assessment and Calibration of Iso-Lrfd Factors for Minimum Facility Offshore Platform in Malaysia. Universiti Teknologi Malaysia, 2019.

73. Li, L.; Li, P.; Liu, Y. Structural Reliability Based Design and Assessment Acceptance Criteria Development for Fixed Offshore Platforms in South China Sea Under Extreme Storm Conditions. In Proceedings of International Conference on Offshore Mechanics and Arctic Engineering; p. V02BT02A044. 
74. Stacey, A.; Birkinshaw, M.; Sharp, J. Life extension issues for ageing offshore installations. In Proceedings of International Conference on Offshore Mechanics and Arctic Engineering; pp. 199-215.

75. Defranco, S.; O'Connor, P.; Puskar, F.; Bucknell, J.R.; Digre, K.A. API RP 2SIM: Recommended practice for structural integrity management of fixed offshore platforms. In Proceedings of Offshore Technology Conference.

76. Ersdal, G.; Ho“ rnlund, E.; Spilde, H. Experience from Norwegian programme on ageing and life extension. In Proceedings of International Conference on Offshore Mechanics and Arctic Engineering; pp. 517-522.

77. Norwegian Oil and Gas Association. 122: Recommended Guidelines for the assessment and documentation of service life extension of facilities. Version: 2008.

78. Selnes, P.O.; Ersdal, G. Industry Developed Guidelines and Standards for Ageing and Life Extension. pp. 433-443.

79. Nezamian, A.; Altmann, J. An oil field structural integrity assessment for re-qualification and life extension. In Proceedings of International Conference on Offshore Mechanics and Arctic Engineering; p. V02BT02A014.

80. Det Norske Veritas, G. Probabilistic methods for planning of inspection for fatigue cracks in offshore structures. DNV GL, Oslo, Norway, Standard No. DNVGL-RP-C210 2015.

81. Ersdal, G.; Selnes, P.O. Life extension of aging petroleum production facilities offshore. In Proceedings of SPE International Conference on Health, Safety and Environment in Oil and Gas Exploration and Production.

82. Kolios, A.; Mytilinou, V.; Lozano-Minguez, E.; Salonitis, K. A comparative study of multiplecriteria decision-making methods under stochastic inputs. Energies 2016, 9, 566.

83. Solland, G.; Sigurdsson, G.; Ghosal, A. Life extension and assessment of existing offshore structures. In Proceedings of SPE Project and Facilities Challenges Conference at METS.

84. Mat Soom, E.; Abu Husain, M.K.; Mohd Zaki, N.I.; Azman, N.U.; Najafian, G. ReliabilityBased Design and Assessment for Lifetime Extension of Ageing Offshore Structures. In Proceedings of Proceedings of the 35th International Conference on Ocean, Offshore and Arctic Engineering, 19-24 June 2016. Busan, South Korea; pp. V003T002A044-V003T002A044.

85. PETRONAS Research and Scientific Services, S.B. Structural Integrity and Inspection Analyses of Old Jackets Reassessment Basis. Part 1. Revision 01. Petronas: Restricted Document. 1999.

86. Abhinav, K.; Saha, N. Coupled hydrodynamic and geotechnical analysis of jacket offshore wind turbine. Soil Dynamics and Earthquake Engineering 2015, 73, 66-79.

87. Abhinav, K.; Saha, N. Dynamic analysis of monopile supported offshore wind turbines. Proceedings of the Institution of Civil Engineers-Geotechnical Engineering 2017, 170, 428-444.

(C) 2019 by the authors. Submitted for possible open access publication under the terms and conditions of the Creative Commons Attribution (CC BY) license (http://creativecommons.org/licenses/by/4.0/). 